\title{
ĐÁNH GIÁ SỰ SAI LỆCH KẾT QUẢ XÉT NGHIỆM DOUBLE TEST VÀ TRIPLE TEST TRONG CÁC ĐIỀU KIỆN BẢO QỦ̉N MẪU KHÁC NHAU
}

\author{
Lê Thị Mai Dung*, Mai Thị Đoan Trang*, Văn Hy Triết*
}

TÓM TẮT

Mục tiêu nghiên cứu: xác định tỷ lệ nguy cơ hóa sinh thay đổi trong xét nghiệm Double test ở các điêu kiện bảo quản mẫu khác nhau thông qua nồng độ các các dấu ấn hóa sinh free beta-hCG, PAPP-A. Đánh giá sự thay đổi nồng độ của AFP, beta-hCG và uẺ trong xét nghiêm Triple test ở các thời gian lưu mấu khác nhau. Đối tượng và phương pháp nghiên cứu: đối tượng gồm 15 mâu huyết thanh của 15 thai phụ mang thai từ 11 tuần đến 13 tuần 6 ngày. Xác định nônng độ free beta-hCG và PAPP-A ở các điều kiện: tách huyết thanh và định lượng trong 12 giờ; bảo quản $2-8^{\circ} \mathrm{C}$ trong 96 và 120 giờ (tách huyết thanh và không tách huyết thanh). Kỹ thuật miễn dịch định lượng trên hệ thống Immulite 2000 và 1000 , phần mềm tính nguy cớ Prisca. Nghiên cứu mô tả, cắt ngang, phân tích so sánh; Xác định giá trị trung vị, so sánh nồng độ AFP, Beta-hCG và uE3 từ 818 kêt quả triple test của phu nứ manng thai từ 15 đến 21 tuần 6 ngày với thời gian lưu mẫu từ 24 giờ đến 96 giờ. Kỹ thuât miễn dich đinh lượng trên hệ thống Immulite 2000, phần mềm tính nguy cơ Prisca. Phân tích số liệu trên phân mềm SPSS. Nơi thực hiện Đại Học Y Dược Thành Phố Hồ Chí Minh. Kết quả: Double test: so sánh với mấu bảo quản 2$7^{\circ} \mathrm{C}$ với mẫu bảo quản 12 giờ ở nhiệt độ phòng thì kết quả là: Sau 96 giờ: free beta-hCG và PAPP-A không có sự thay đổi giá trị trung vị nồng độ, nguy cơ hóa sinh giảm $10 \%$ ở mẫu tách và không tách huyết thanh. Sau 120 giờ: trung vị nồng độ PAPP-A tuân thai 11 tăng $16,1 \%$ (mẫu tách huyết thanh); tăng 3,5\% (không tách huyết thanh ); Trung vị nồng độ Free beta-hCG không thay đổi đối với tất cá tuân thai. Nguy cơ hóa sinh lần lượt giảm $15 \%$ ở mẫu tách huyết thanh và $11 \%$ ở mấu không tách huyết thanh. Triple test: nồng độ AFP giảm với các mẫu lưu trữ 48 giờ $(21,4 \%)$, giảm ở 72 giờ (23\%) và tăng khi lưu trữ 96 giớ (31.9\%). Nồng độ Beta-hCG tăng dần theo thời gian lưu trữ mẫu 48 giờ (38\%), 72 giờ $(37,2 \%), 96$ giờ $(47,9 \%)$. Nồng độ uE3 tăng trong mấu lưu 48 giờ $(41,9 \%)$, không thay đổi ở 72 giờ và 96 giờ, tuy nhiên sư thay đổi chỉ xảy ra ở một số tuần thai. Kết luân: mấu thử được bảo quản ở $2-8^{\circ} \mathrm{C}$ trong 96 giờ khổng làm thay đổi giá trị nồng độ free beta-hCG, PAPP-A nhưng là̃m giảm $10 \%$ giá trị nguy cơ hóa sinh. Khi bảo quản mẫu 120 giờ ở $2-8^{\circ} \mathrm{C}$ nồng độ free beta-hCG không thay đổi, trung vị nồng độ PAPP-A tăng ở tuần thai thứ 11 cao nhất là $16,1 \%$ và nguy cơ sinh hóa giảm khoảng $15 \%$. Thời gian lưu mẫu 48 giờ dẫn đến nồng AFP giảm và UE3 tăng. Lưu mẫu 72 giờ và 96

*Đại Học Y Dược Thành phố Hồ Chí Minh Chịu trách nhiệm chính: Lê Thị Mai Dung Email: lethimaidung@ump.edu.vn Ngày nhận bài: 10.9.2021

Ngày phản biện khoa học: 10.11.2021

Ngày duyệt bài: 16.11.2021 giờ làm tăng nồng độ AFP. Nồng độ Beta-hCG tăng dần theo thời gian lưu trữ mẫu 48,72,96 giờ.

\section{SUMMARY \\ EVALUATING DEVIATIONS IN DOUBLE TEST AND TRIPLE TEST RESULS UNDER DIFFERENT SAMPLE STORAGE CONDITIONS}

Objective: To determine the rate of technical deviation in biochemical risk calculated by Double test under different sample storage conditions using the concentrations of biochemical markers free beta- hCG and PAPP-A; To evaluate the change in the concentrations of AFP, beta-hCG, and uE3 determined by triple test at different storage periods. Subjects \& methods: The descriptive, comparative crosssectional study was conducted at Ho Chi Minh City University of Medicine and Pharmacy. Double test: Serum samples were obtained from 15 women 11 13 weeks into their pregnancies who underwent firsttrimester prenatal screening. Free beta-hCG and PAPP-A concentrations were determined under the following storage conditions: separated and analyzed within 12 hours; stored at $2-8^{\circ} \mathrm{C}$ for 96 hours and 120 hours (with and without serum separation). Triple test: Using retrospective data from 818 pregnant women at 15-21 weeks and 6 days of gestation, the concentrations of AFP, beta-hCG, and uE3 were compared among four different sample groups with storage times of 24, 48, 72, and 96 hours. Quantitative immunoassays were performed on Immulite 2000 and 1000 systems, and the risks were calculated using PRISCA 5.0. Further data analysis was performed on SPSS. Results: Double test: Compared to samples analyzed within 12 hours at room temperature, we observed the following in samples stored at $2-7^{\circ} \mathrm{C}$. After 96 hours: the median free betahCG and PAPP-A concentrations showed no statistically significant difference; the calculated biochemical risks were $10 \%$ lower in both separated and unseparated samples. After 120 hours: the median PAPP-A concentration at 11 weeks of gestation was $16.1 \%$ higher in serum separated samples and $3.5 \%$ higher in unseparated samples; no difference was observed in the median free beta-hCG concentration across all gestational ages. The biochemical risk was $15 \%$ and $11 \%$ lower in separated and non-separated samples, respectively. Triple test: Compared to 24-hour storage, AFP concentration was $21.4 \%$ lower at 48 -hour storage, $23 \%$ lower at 72 -hour storage, and $31,9 \%$ higher at 96 -hour storage. BetahCG concentration showed gradually increasing values with longer storage times: $38 \%$ higher at 48 hours, $37.2 \%$ higher at 72 hours, and $47.9 \%$ higher at 96 hours. UE3 concentration was $41.9 . \%$ higher at 48 hours and unchanged at 72 hours and 96 hours. However, this change only occurred at a few specific 
gestational weeks. Conclusion: Storing samples at 2$8^{\circ} \mathrm{C}$ for 96 hours did not alter free beta-hCG and PAPP-A concentrations; however, the calculated biochemical risk was lowered by $10 \%$. When samples were stored for 120 hours at $2-8^{\circ} \mathrm{C}$, the free beta-hCG concentration did not change, the median PAPP-A concentration was $16.1 \%$ higher at 11 weeks of gestation, and the biochemical risk was lowered by approximately $15 \%$. A 48 -hour storage time resulted in lower AFP and higher UE3 levels. Storage times of 72 hours and 96 hours increased AFP concentration. Beta-hCG concentration gradually increased with longer sample storage times at 48, 72, and 96 hours compared to 24 hours.

Keyword: Prenatal screening test, Double test, Triple test, biochemical risk change.

\section{I. ĐĂT VẤN ĐỀ}

Xét nghiệm sàng lọc trước sinh hội chứng Down cho phụ nữ mang thai gồm 2 giai đoạn: Double test (11 tuần đến 13 tuần 6 ngày) và Triple test (15 tuần đến 21 tuần 6 ngày). Mục đích của xét nghiệm là xác định tỷ lệ nguy cơ thai phụ sinh con bị hội chứng Down thông qua việc tính toán kết hợp các thông số dấu ấn hóa sinh, độ mờ da gáy (NT) và tuổi thai phụ. Xét nghiệm liên quan đến hội chứng Down bao gồm nhóm xét nghiệm sàng lọc và xét nghiệm chẩn đoán. Xét nghiệm sàng lọc được thực hiện trên số đông dân để tìm ra những thai phụ có nguy cơ cao mang thai hội chứng Down. Xét nghiêm chẩn đoán được thực hiện sau giai đọan tầm soát và trên phụ nữ có kểt quả nguy cơ cao. Lợi ích từ việc sàng lọc trên số đông thai phụ sẽ hạn chế rủi ro khi dùng các thủ thuật xâm lấn trong xét nghiệm chẩn đoán như sinh thiết gai nhau, chọc ối. Hiện nay chương trình sàng lọc hội chứng Down ở Việt Nam gồm hai bộ xét nghiệm Double test và Triple test. Việc thực hiện tính toán nguy cơ dựa trên các thông số tích hợp như tuổi mẹ, nồng độhai dấu ấn Free $\beta$-hCG và PAPP$A$ (Double test) và ba dấu ấn Free $\beta-h C G$, uE3 và AFP (Triple test); độ mờ da gáy (NT), từ đó xác định nguy cơ thai nhi mắc hội chứng Down. Độ chính xác của kết quả phụ thuộc vào các thông số sàng loc được tích hợp trên phần mềm tính nguy cơ trong đó dấu ấn hóa sinh là rất quan trọng. Kết quả nồng độ free beta-hCG, PAPP-A, beta hCG, uE3 và AFP có ảnh hưởng trực tiếp đến việc tính toán kết quả nguy cớ, khi nồng độ các chất thay đổi do việc lây và bảo quản mẫu thử không đảm bảo sẽ ảnh hưởng đến giá trị nguy cơ sau cùng. Khi điều kiện thu nhận mẫu, bảo quản mẫu không được đảm bảo như : tách hoặc không tách huyết thanh, bảo quản ở nhiệt độ không thích hợp sẽ ảnh hưởng đến kết quả xét nghiệm. Do đó cần thiết phải đưa ra các khuyến cáo hay chính xác hơn là các quy định chặt chẽ về vân đề bảo quản mẫu thử đối với xét nghiệm sàng lọc trước sinh hội chứng Down nhằm đem lại kết quả có độ tin cây cao nhất. Mục tiêu nghiên cứu: xác định tỷ lệ nguy cơ hóa sinh thay đổi trong xét nghiêm Double test ở các điều kiên bảo quản mấu khác nhau thông qua nồng độ các các dấu ấn hóa sinh free beta-hCG, PAPP-A. Đánh giá sự thay đổi nồng độ của AFP, beta-hCG và UE3 trong xét nghiệm Triple test ở các thời gian lưu mẫu khác nhau.

\section{II. ĐỐI TƯợNG VÀ PHƯƠNG PHÁP NGHIÊN CỨU}

Phương pháp nghiên cứu: nghiên cứu cắt ngang, so sánh từng nhóm trong một mẫu nghiên cứu; Biến số chính: nồng độ free $\beta$-hCG $(\mathrm{ng} / \mathrm{ml})$, nồng độ PAPP-A ( $\mathrm{mUI} / \mathrm{ml})$, AFP, betahCG và $u E 3$, định lượng trên máy miễn dịch tự động IMMULITE 2000; biến số phụ: các thông số siêu âm chiều dài đầu mông (CRL $-\mathrm{mm})$, đường kính lưỡng đỉnh (BPD - mm), độ mờ da gáy (NT - mm), tuần thai (tuần + ngày). Phương pháp thống kế: Sử dụng phép kiểm định Wilcoxon cho mẫu bắt cặp trong dữ liệu khônng phải phân phối chuẩn. Giây phép y đức: Số 289/HĐĐĐ-ĐHYD. Thời gian và địa diểm nghiên cứu: Đại Hoc Y Dược Thành phố Hồ Chí Minh từ tháng 12 nằm 2020 đến tháng 8 năm 2021.

Đối tượng nghiên cứu: Double test: mẫu huyết thanh của 15 thai phụ mang thai từ 11 tuần đến 13 tuần 6 ngày.Triple test: kết quả xét nghiệm triple test của 818 thai phụ trên dữ liệu lưu trữ của phần mềm Prisca có tuần thai từ 15 tuần đến 21 tuần 6 ngày.

Tiêu chuẩn chơn mẫu: Được bác sĩ chỉ định làm xét nghiệm sàng lọc trước sinh hội chứng Down. Có đầy đủ các thồng số siêu âm: chiều dài đầu mông (CRL), đường kính lưỡng đỉnh (BPD) và độ mờ da gáy (NT) do bác sĩ siêu âm cung cấp.

Tiêu chuẩn loại mẫu: Mẫu máu từ các thai phụ: đa thai, hút thuốc, tiểu đường và thụ tinh trong ống nghiệm, mẫu máu bị tiêu huyết, có chất chống đông, thời gian và cách thức bảo quản không đúng.

Cách tiến hành: Khai thác thông tin thai phụ được chỉ định làm xét nghiệm sàng lọc bao gồm tin thai phụ theo tờ khai thông tin: họ tên, ngày sinh, cân nặng, ngày lấy mấu, ngày siêu âm...các thông tin hiệu chỉnh. Các thông số siêu âm: chiều dài đầu mông ( $C R L)$, đường kính lưỡng đỉnh (BPD), độ mờ da gáy (NT), tuần thai được bác sĩ siêu âm cung cấp qua kết quả siêu âm. Định lượng các dấu ấn hóa sinh trên các mẫu huyết thanh của thai phụ bao gồm free beta-hCG, PAPP-A, beta -hCG, AFP, uE3 theo kỹ 
thuật miễn dịch sandwich tuân thủ các bước: Xây dựng đường chuẩn cho các xét nghiệm và hiệu chỉnh trên nguyên tắc: "Adjustment" tương tự như "2 point calibration". Thức hiên nôi kiểm với huyết thanh kiểm tra của các hãng Randox, xây dựng lại khoảng tham chiếu nội kiểm cho máy Immulite 2000 bằng cách đo lặp lại 6 lần một ngày liên tục trong 10 ngày liên tiếp cho khoảng \%CV nhỏ hơn khoảng \%CV của nhà sản xuất cung cấp.

Bảo quản mẫu thử: mẫu thử cho nghiên cứu Double test chia làm 5 nhóm thực hiện: Nhóm 1- Mẫu tách huyết thanh và phân tích trong 12 giờ; Nhóm 2 - Mẫu tách huyết thanh và bảo quản $\left(2-8^{\circ} \mathrm{C}\right)$ trong 96 giờ; Nhóm 3- Mẫu không tách huyết thanh và bảo quản $\left(2-8^{\circ} \mathrm{C}\right)$ trong 96 giờ; Nhóm 4- Mẫu tách huyết thanh và bảo quản $\left(2-8^{\circ} \mathrm{C}\right)$ trong 120 giờ; Nhóm 5 - Mẫu không tách huyết thanh và bảo quản $\left(2-8^{\circ} \mathrm{C}\right)$ trong 120 giờ. Thống kê kết quả nồng độ AFP, beta-hCG và uE3 của 818 thai phụ được chia thành 4 nhóm: Nhóm I: Thời gian lưu mấu $<24$ giờ; Nhóm II: Thời gian lưu mẫu từ 24 giờ đến dưới 48 giờ; Nhóm III: Thời gian lưu mẫu từ 48 giờ đến dưới 72 giờ; Nhóm IV: Thời gian lưu mẫu từ 72 giờ đến dưới 96 giờ. Thiết bị và thuốc thử: máy miễn dịch tự động IMMULITE 2000 và IMMULINE 1000 và bộ thuốc thử của hãng Siemmens. Mẫu huyết thanh kiểm tra Maternal Control của hãng Randox. Xử lý số liệu: thống kê kết quả và phân tích bằng phần mềm SPSS, sử dụng kiểm định phi tham số Wilcoxon cho Double test và Mann-Whitney cho Triple test (so sánh các trung vị cho phân phối không chuẩn). Chọn mức ý nghĩa thống kê là $p<0,05$.

\section{KẾT QUẢ NGHIÊN CỨU}

Phân bố tuổi me và tuổi thai: Thai phu dưới 35 tuổi chiếm 93,3\% (Double test) và $88,75 \%$ (Triple test); trong đó nhóm thai phụ trên 35 tuổi chiếm tỷ lệ nhỏ.

Kết quả định lượng Free beta-hCG và PAPP-A ở từng điêu kiện bảo quản mẫu khác nhau trong nghiên cứu Double test

Qui ước: Nhóm 1: định lượng ngay trong 12 giờ; Nhóm 2: tách huyết thanh bảo $\left(2-8^{\circ} \mathrm{C}\right)$ trong 96 giờ; Nhóm 3: không tách huyết thanh bảo quản $\left(2-8^{\circ} \mathrm{C}\right)$ trong 96 giờ; Nhóm 4: tách huyết thanh bảo quản $\left(2-8^{\circ} \mathrm{C}\right)$ trong 120 giờ; Nhóm 5 : không tách huyết thanh bảo quản $\left(2-8^{\circ} \mathrm{C}\right)$ trong 120 giờ.

Bảng 1. So sánh nồng độ Free beta-hcG, PAPP-A giữa nhóm bảo quản 96 giờ và 120 giờ với nhóm bảo quản 12 giờ

\begin{tabular}{|c|c|c|c|c|c|}
\hline $\begin{array}{c}\text { giơ vơ nhồn } \\
\text { thai }\end{array}$ & \multirow{2}{*}{ Nhóm } & Trung vị & $\begin{array}{c}\text { Khoảng phân } \\
\text { phối }\end{array}$ & \multicolumn{2}{c|}{ PAPP-A(mUI/ml) } \\
\cline { 2 - 6 } & & 92,8 & $26,6-110$ & 3,09 & $1,71-4,82$ \\
\hline \multirow{4}{*}{ Tuân 11 } & 1 & 70,5 & $28,5-174$ & 3,67 & $1,7-5,07$ \\
\cline { 2 - 6 } & 2 & 69,3 & $28,9-165$ & 3,5 & $1,81-4,42$ \\
\cline { 2 - 6 } & 3 & 76,5 & $26,7-177$ & $\mathbf{3 , 5 9}$ & $1,95-5,49$ \\
\cline { 2 - 6 } & 4 & 75,7 & $23,7-182$ & $\mathbf{3 , 2}$ & $1,85-4,91$ \\
\cline { 2 - 6 } & 5 & 60,75 & $29,1-92,7$ & 3,95 & $1,28-7,19$ \\
\hline \multirow{4}{*}{ Tuần 12 } & 1 & 56 & $21,6-148$ & 3,505 & $1,34-6,26$ \\
\cline { 2 - 6 } & 2 & 59,15 & $21-150$ & 3,75 & $1,28-6,62$ \\
\cline { 2 - 6 } & 3 & 59,8 & $25,8-148$ & 3,735 & $1,36-6,41$ \\
\cline { 2 - 6 } & 4 & 61,25 & $26,9-150$ & 3,525 & $1,22-7,53$ \\
\hline \multirow{4}{*}{ Quý 1 } & 5 & 64,1 & $26,6-110$ & 3,29 & $1,28-7,19$ \\
\cline { 2 - 6 } & 1 & 68,4 & $21,6-174$ & 3,67 & $1,34-6,26$ \\
\cline { 2 - 6 } & 2 & 67,9 & $21-165$ & 3,74 & $1,28-6,62$ \\
\cline { 2 - 6 } & 3 & 60,2 & $25,8-177$ & 3,59 & $1,36-6,41$ \\
\cline { 2 - 6 } & 4 & 64 & $23,7-182$ & 3,4 & $1,22-7,53$ \\
\hline
\end{tabular}

Sự thay đối nồng độ free beta-hCG và PAPP-A trong các điều kiện tách huyết thanh và không tách huyết thanh khi bảo quản $\left(2-8^{\circ} \mathrm{C}\right)$ trong 96 giờ so với mẫu thực hiện ngay trong 12 giờ không có ý nghĩa thống kê cho tất cả tuần thai $(p>0,05)$.
Trong 120 giờ, nồng độ PAPP-A tăng đối với mẫu tách và không tách huyết thanh ở tuần thai 11 (trung vị giữa các nhóm lần lượt là 3,09 $\mathrm{mUI} / \mathrm{ml} ; 3,59 \mathrm{mUI} / \mathrm{ml}$ và $3,2 \mathrm{mUI} / \mathrm{ml})(\mathrm{p}<0,05)$. Beta-hCG thay đổi không có ý nghĩa thống kê. $(\mathrm{P}>0,05)$

Bảng 2. Nguy cơ hóa sinh thay đổi theo giá trị PAPP-A Chi số 


\begin{tabular}{|c|c|c|c|c|c|}
\hline \multicolumn{2}{|c|}{} & Nhóm 1-2 & Nhóm 1-3 & Nhóm 1-4 & Nhóm 1-5 \\
\hline Tuần 11 & $\begin{array}{c}\text { Trung bình \% \%guy } \\
\text { cơ thay đổi }\end{array}$ & $\mathbf{1 8 \%} \downarrow$ & $\mathbf{1 8 \%} \downarrow$ & $\mathbf{2 6 \%} \downarrow$ & $\mathbf{2 2 \%} \downarrow$ \\
\hline Tuần 12 & $\begin{array}{c}\text { Trung bình \% nguy } \\
\text { cơ thay đổi }\end{array}$ & $4 \% \downarrow$ & $4 \% \downarrow$ & $7 \% \downarrow$ & $3 \% \downarrow$ \\
\hline Quý 1 & $\begin{array}{c}\text { Trung bình \% nguy } \\
\text { cơ thay đổi }\end{array}$ & $\mathbf{1 0 \%} \downarrow$ & $\mathbf{1 0 \%} \downarrow$ & $\mathbf{1 5 \%} \downarrow$ & $\mathbf{1 1 \%} \downarrow$ \\
\hline
\end{tabular}

Nguy cơ hóa sinh thay đổi dưới sự ảnh hưởng của PAPP-A có ý nghĩa thống kê $(p<0,05)$ ở tuần thai 11 và quý 1 . Đối với mẫu tách huyết thanh và không tách huyết thanh nguy cơ đều giảm $18 \%$ (tuần thai 11) và $10 \%$ (quý 1 ) ở 96 giờ. Sau 120 giờ mẩu tách huyết thanh giảm $26 \%$, mẫu không tách huyết thanh giảm $22 \%$ (tuần thai 11 ), nếu tính cho cả quí 1 thì mẫu tách huyết thanh giảm $15 \%$, mầu không tách huyết thanh giảm $11 \%$ (quý 1 ).

Bảng 3. Nguy cơ hóa sinh thay đồi theo free beta-hCG

\begin{tabular}{|c|c|c|c|c|c|}
\hline \multicolumn{2}{|c|}{ Chỉ số } & \multicolumn{2}{c|}{ Bảo quản 96 giờ } & \multicolumn{2}{c|}{ Bảo quản 120 giờ } \\
\cline { 3 - 6 } Tuần 11 & $\begin{array}{c}\text { Trung bình \% \% nguy } \\
\text { cơ thay đổi }\end{array}$ & $30 \% \uparrow$ & $22 \% \uparrow$ & $21 \% \uparrow$ & $28 \% \uparrow$ \\
\hline Tuần 12 & $\begin{array}{c}\text { Trung bình \% nguy } \\
\text { cơ thay đổi }\end{array}$ & $39 \% \uparrow$ & $41 \% \uparrow$ & $50 \% \uparrow$ & $53 \% \uparrow$ \\
\hline Quý 1 & $\begin{array}{c}\text { Trung bình \% nguy } \\
\text { cơ thay đổi }\end{array}$ & $35 \% \uparrow$ & $33 \% \uparrow$ & $38 \% \uparrow$ & $43 \% \uparrow$ \\
\hline
\end{tabular}

Nguy cơ hóa sinh thay đổi dưới sự ảnh hưởng của free beta-hCG là không có ý nghĩa thống kê $(p>0,05)$ ở tất cả tuần thai trong quý 1 đối với mẫu tách và không tách huyết thanh.

Giá trị nồng độ của AFP, beta-hCG và uE3 ở từng thời gian bảo quản mẫu khác nhau trong nghiên cứu Triple test

Bảng 4. So sánh nồng độ giữa thời gian lưu mẫu 48 giờ,72 giờ và 96 giờ với 24 giờ

\begin{tabular}{|c|c|c|c|c|c|c|c|}
\hline \multirow[b]{2}{*}{$\begin{array}{l}\text { Tuân } \\
\text { thai }\end{array}$} & \multirow[b]{2}{*}{ Nhóm } & \multicolumn{2}{|c|}{ AFP(IU/mL) } & \multicolumn{2}{|c|}{ Beta - hCG $(\mathrm{mIU} / \mathrm{mL})$} & \multicolumn{2}{|c|}{ uE3 $(\mathrm{ng} / \mathrm{mL})$} \\
\hline & & $\begin{array}{c}\text { Trung } \\
\text { vị }\end{array}$ & $\begin{array}{l}\text { Khoảng } \\
\text { phân } \\
\text { phối }\end{array}$ & $\underset{\text { vị }}{\text { Trung }}$ & $\begin{array}{l}\text { Khoảng } \\
\text { phân phối }\end{array}$ & Trung vị & $\begin{array}{c}\text { Khoảng } \\
\text { phân } \\
\text { phối }\end{array}$ \\
\hline \multirow{4}{*}{ Tuân 15} & I & 32,6 & $12-56,6$ & 40810 & $22517-104542$ & 0,31 & $0,21-0,78$ \\
\hline & II & 32,8 & $19,3-80,2$ & 45136 & $21989-75856$ & 0,44 & $0,22-0,74$ \\
\hline & III & 40,1 & $21,5-130$ & 56025 & $21527-86570$ & 0,28 & $0,07-1,01$ \\
\hline & IV & 36,8 & $18,1-108$ & 60383 & $17684-163788$ & 0,29 & $0,07-0,93$ \\
\hline \multirow{4}{*}{ Tuần 16} & I & 37,2 & $17,7-350$ & 33028 & $7229-70616$ & 0,52 & $0,28-1,22$ \\
\hline & II & 32,8 & $17,9-53$ & 32833 & $14523-87492$ & 0,52 & $0,17-1,19$ \\
\hline & III & 39,2 & $17,9-86,1$ & 35988 & $17391-111943$ & 0,46 & $0,09-1,44$ \\
\hline & IV & 49,1 & $22,4-87,2$ & 42423 & $14006-69182$ & 0,62 & $0,29-1,39$ \\
\hline \multirow{4}{*}{ Tuân 17} & I & 49,5 & $18,3-94,9$ & 30537 & $11750-61264$ & 0,79 & $0,21-1,61$ \\
\hline & II & 38,9 & $19,3-61$ & 27193 & 9905-58207 & 0,87 & $0,42-2,77$ \\
\hline & III & 46,8 & $25,3-107$ & 28980 & $9185-70572$ & 0,66 & $0,24-1,60$ \\
\hline & IV & 43,6 & $20,1-142$ & 29120 & $6386-61109$ & 0,83 & $0,42-1,97$ \\
\hline \multirow{4}{*}{ Tuần 18} & I & 54,9 & $12,1-109$ & 25742 & $9373-77250$ & 1,17 & $0,07-2,15$ \\
\hline & II & 45,9 & $20,5-103$ & 29633 & $7334-62632$ & 0,92 & $0,17-1,91$ \\
\hline & III & 60,2 & $29,6-134$ & 32020 & $9960-63152$ & 1,18 & $0,33-2,44$ \\
\hline & IV & 54,9 & $14,4-270$ & 25034 & $7917-121611$ & 0,99 & $0,1-2,31$ \\
\hline \multirow{4}{*}{ Tuân 19} & I & 70,6 & $38,3-120$ & 20042 & $8113-44857$ & 1,39 & $0,6-3,5$ \\
\hline & II & 74,5 & $24,5-184$ & 27644 & $7229-71691$ & 1,32 & $0,46-2,39$ \\
\hline & III & 73 & $20,5-174$ & 24965 & $8949-63276$ & 1,35 & $0,69-3,91$ \\
\hline & IV & 60,7 & $33,8-142$ & 25019 & $7884-102716$ & 1,29 & $0,69-2,54$ \\
\hline \multirow{4}{*}{ Tuânn 20} & $\mathrm{I}$ & 81 & $30,4-209$ & 21434 & $5169-53488$ & 1,97 & $1,21-6,24$ \\
\hline & II & 73,2 & $35,1-151$ & 21359 & $7229-205000$ & 2,08 & $1,14-5,41$ \\
\hline & III & 74,4 & $34,3-144$ & 25922 & $4929-43826$ & 1,93 & $0,79-5,05$ \\
\hline & IV & 72,9 & $16,1-213$ & 23999 & $7229-44153$ & 1,94 & $0,66-4,52$ \\
\hline
\end{tabular}




\begin{tabular}{|c|c|c|c|c|c|c|c|}
\hline \multirow{4}{*}{ Tuân 21 } & I & $\mathbf{1 2 6 , 5}$ & $77,8-152$ & 19004 & $7229-43784$ & 2,44 & $2,12-3,27$ \\
\cline { 2 - 8 } & II & 89,9 & $57,6-154$ & 23371 & $5046-80775$ & 2,35 & $1,23-4,23$ \\
\cline { 2 - 8 } & III & $\mathbf{7 5 , 9}$ & $30,6-119$ & 24118 & $6811-43464$ & 2,22 & $1,23-3,17$ \\
\cline { 2 - 8 } & IV & $\mathbf{7 2 , 9}$ & $67,1-114$ & 19950 & $16503-22067$ & 2,49 & $1,53-4,2$ \\
\hline
\end{tabular}

Nhóm II: lưu mẫu trong vòng 24 giờ; Nhóm II: lưu mẫu trong vòng 48 giờ; Nhóm III: lưu mẫu trong vòng 72 giờ; Nhóm IV: Iưu mẫu trong vòng 96 giờ;

Thời gian lưu mẫu 48 giờ: AFP: giá trị trung vị nồng độ là $38,9 \mathrm{IU} / \mathrm{mL}$ giảm so với giá trị trung vị nồng độ ở 24 giờ $(49,5 \mathrm{IU} / \mathrm{mL})$ ở tuần thai 17 . Trung vị Beta-hCG là $27644 \mathrm{mIU} / \mathrm{mL}$ so với 20042 $\mathrm{mIU} / \mathrm{mL}$ (24 giờ) ở tuần thai 19 . UE3, tăng từ $0,31 \mathrm{ng} / \mathrm{mL}$ (24 giờ) lên $0,44 \mathrm{ng} / \mathrm{mL}$ (48 giờ) ở tuần thai 15 , giảm từ $1,17 \mathrm{ng} / \mathrm{mL}$ (24 giờ) xuống $0,92 \mathrm{ng} / \mathrm{mL}$ ở tuần thai 18 . Tất cả đều được so sánh với mức ý nghĩa thống kê $(p<0,05)$.

Thời gian lưu mẫu 72 giờ: AFP: giá trị trung vị nồng độ là $40,1 \mathrm{IU} / \mathrm{mL}$ ở tuần thai thứ 15 tăng lên so với 32,6 IU/mL (24 giờ) và giảm từ 126,5 $\mathrm{IU} / \mathrm{mL}$ (24 giờ) xuống 75,9 IU/mL (72 giờ) ở tuần thai 21. Beta-hCG: tăng từ $40810 \mathrm{mIU} / \mathrm{mL}$ (24 giờ) lên $56025 \mathrm{mIU} / \mathrm{mL}$ (72 giờ) ở tuần thai thứ 15, từ $20042 \mathrm{mIU} / \mathrm{mL}$ (24 giờ) lên 24965 $\mathrm{mIU} / \mathrm{mL}$ (72 giờ) ở tuần thai 19. $(\mathrm{p}<0,05)$. UE3, sự khác biệt về nồng độ là không có ý nghĩa thống kê trong tất cả tuần thai $(p>0,05)$.

Thời gian lưu mẫu 96 giờ: AFP: giá trị trung vị nồng độ tăng từ 37,2 IU/mL (24 giờ) lên 49,1 IU $/ \mathrm{mL}$ ( 96 giờ) ở tuần thai 16 . Beta-hCG, tăng từ 40810mIU/mL (24 giờ) lên $60383 \mathrm{mIU} / \mathrm{mL}$ (96 giờ) ở tuần thai $15(\mathrm{p}<0,05)$. Sự khác biệt về nồng độ uE3 là không có ý nghĩa thống kê trong các tuân thai. $(p>0,05)$.

\section{BÀN LUẬN}

Đối với nghiên cứu Double test: nghiên cứu trước đây của Lê Thị Mai Dung và Lương Trần Minh Tiến $(2020)^{(1)}$ đã thực hiện bảo quản mẫu ở nhiệt độ $\left(2-8^{\circ} \mathrm{C}\right)$ tới 72 giờ nhưng nồng độ free beta-hCG và PAPP-A vẫn chưa thay đổi trên cả mẫu tách huyết thanh và không tách huyết thanh. Điều này không khác biệt với nghiên cứu của Văn Hy Triết $(2014)^{(2)}$ có nhiệt độ bảo quản trung bình $3^{\circ} \mathrm{C}$ với thời gian 72 giờ (không thây sự khác biệt đối với mẫu tách huyết thanh). Tiếp tục nghiên cứu trên, chúng tôi kéo dài thời giản bảo quản này tới 120 giờ và quan sát sự thay đổi nồng độ free beta-hCg, PAPP-A cũng trên mẫu tách và không tách huyết thanh ở $2-8^{\circ} \mathrm{C}$ (nhiệt độ trung bình $4,6^{\circ} \mathrm{C}$ ). Chúng tôi nhận thấy, sự thay đổi không có ý nghĩa thống kê ở hầu hết các tuần thai. Tuy nhiên, bảo quản 120 giờ, sự thay đổi nồng độ PAPP-A ở tuần thai
11 là có ý nghĩa thống kê trên cả mẫu tách và không tách huyết thanh. Phân tích giá trị trung vị nhận thấy giá trị tăng $16 \%$ (tách huyết thanh), tăng 3,55\% (không tách huyết thanh) (Bảng 1). Với mức CV\% của phương pháp đo là $10 \%$ thì giá trị phân trăm ở nhóm tách huyết thanh vượt qua sai số của máy nhưng không vượt nhiều, nhóm không tách huyết thanh thì thẩp hơn so với khoảng biến thiên này. Do đó sự tăng lên này là có ghi nhận ở nhóm tách huyết thanh nhưng không nhiều chỉ khoảng $6 \%$, cần làm thêm với số lượng mẫu lớn hơn để đánh giá thêm. Nghiên cứu của Cruz và cộng sự (2010)(3), với mục đích kiểm tra sự ảnh hưởng của nhiệt độ lên nồng độ free beta-hCG, PAPP-A trong khoảng thời gian từ 1 đến 8 ngày trên 10 mẫu máu không tách huyết thanh và tách huyết thanh. Kết quả sau 8 ngày bảo quản ở $4^{\circ} \mathrm{C}$ nồng độ free beta-hCG không thay đổi và PAPP-A có sự thay đổi tăng $<10 \%$. Trong khi đó mẫu để ở $20^{\circ} \mathrm{C}$ và $40^{\circ} \mathrm{C}$ thì PAPPA chỉ thay đổi $10 \%$ khi thời gian bảo quản là 4 ngày, free beta-hCG có giá trị tăng đáng kể. Điều này cho thấy có sự phù hợp với nghiên cứu của chúng tôi khi có sự tăng nồng độ PAPP-A ở tuân 11 thai kỳ là $16 \%$ sau 5 ngày $(120$ giờ) đồng thời giá trị Free beta-hCG cũng không thay đổi sau 5 ngày khi được bảo quản ở $2-8^{\circ} \mathrm{C}$. Bên cạnh đó, còn có các nghiên cứu khác như: nghiên cứu của Geralyn M.Lambert - Messerlian và cộng sự (2006)(6) cho thây rằng, nồng độ PAPP-A và free beta-hCG giữ ổn định lên tới 9 ngày ở mẫu tách huyết thanh; trong nghiên cứu của Nicholas J.Cowans và cộng sự (2010)(8), khi bảo quản ở $3^{\circ} \mathrm{C}$, nồng độ PAPP-A ổn định trong 142 ngày, và Free beta-hCG ổn định trong 94 ngày đối với mẫu tách huyết thanh, cả hai nồng độ PAPP-A và Free beta-hCG đều ổn định lên tới 72 giờ đối với mẫu không tách huyết thanh. Ở nghiên cứu của chúng tôi tỷ lệ \% thay đổi tăng của PAPP-A khi tách huyết thanh lại cao hơn khi không tách huyết thanh, điều này cần được xem xét lại và thực hiện với số lượng mẫu nhiều hơn trong các nghiên cứu tiếp theo.

Sự thay đổi tỷ lệ nguy cơ hóa sinh. Chúng tôi đánh giá sự thay đổi nguy cơ hóa sinh thông qua sự tác động của từng dấu ấn hóa sinh PAPP$A$ và free beta-hCG, với sự tăng lên về hiệu số MoM PAPP-A 0,209 (tách huyết thanh) và 0,127 (không tách huyết thanh) sẽ thay đổi giá trị nguy 
cơ hóa sinh tương ứng giảm $26 \%$ và $22 \%$ (tuần thai 11 ); giảm $15 \%$ và $11 \%$ (quý 1 ). Điều này cho thây, khi bảo quản mẫu với thời gian kéo dài 120 giờ có khả năng gây âm tính giả với một số trường hợp khi nguy cơ nằm gần ngưỡng cắt dù là khi được bảo quản ở nhiệt độ $2-8^{\circ} \mathrm{C}$.

Đối với nghiên cứu Triple test: sự thay đổi nồng độ của các dấu ấn hóa sinh bao gồm: mẫu bảo quản 48 giờ đã thấy sự thay đổi, trong Bảng 6, nồng độ AFP giảm $21 \%$ (tuần thai 17 ), betahCG tăng $38 \%$ (tuần thai 19 ), uE3 tăng $42 \%$ (tuần thai 15 ) và giảm $21 \%$ (tuần thai 18 ; trong Bảng 7, mấu bảo quản 72 giờ, nồng độ AFP tăng $23 \%$ (tuần thai 15 ) và giảm $40 \%$ ( tuần thai 21 ), beta hCG tăng $37 \%$ (tuần thai 15 ) và $25 \%$ (tuân thai 19); trong Bảng 8, mẫu bảo quản 96 giờ, nồng độ AFP tăng $32 \%$ (tuần thai 16 ), beta-hCG tăng 48\% (tuần thai 15 ).

Mặc dù có sự dao động về sự thay đổi giá trị trung vị của các thông số hóa sinh trong các tuần thai ở các điều kiện bảo quản mấu khác nhau, xu hướng nồng độ Beta-hCG tăng lên khi thời gian bảo quản mẫu kéo dài, uE3, AFP có sự dao động. So với nghiên cứu của Jacques Masse'và cộng sự (2000)(4), AFP và uE3 ổn định trong huyết thanh với thời gian vận chuyển đến 72 giờ ở môi trường nhiệt độ mồi trường xung quanh, trong khi nồng độ $\mathrm{t}$-hCG và free betahCG tăng lên (đều 10\%). Như vậy xu hướng nồng độ beta-hCG tăng lên theo thời gian bảo quản là tương đồng giữa nghiên cứu của chúng tôi và nghiên cứu của Jacques Masse' và cộng sự. Riêng đối với AFP và uE3 chúng tôi có kết quả dao động tăng và giảm trong một số tuần thai ở các điều kiện thời gian bảo guản mẫu khác nhau không theo qui luật. Các mấu ở quí 2 của chúng tôi được lấy trên cơ sở nghiên cứu cắt ngang với giá trị nồng độ của các mấu khác nhau có cùng tuần thai và̀ cùng thời gian bảo quản, không theo dõi được sự thay đổi riêng từng mẫu qua từng thời gian bảo quản, và cũng không biết chính xác các mẫu có được bảo quản đúng theo khuyến cáo hay không.

Nghiên cứu của Louise $\mathrm{F}$ Brown và cộng sự (2011) ${ }^{(7)}$, sự thay đổi không có ý nghĩa thống kề đối với nồng độ InhA, uE3 giữa thời điểm phân tích ban đầu (2 giờ) so với $1,3,5$, và 7 ngày đối với mẫu tách huyết thanh và không tách huyết thanh. uE3 và InhA ổn định lên tới 7 ngày trong mẫu tách huyết thanh $\left(22^{\circ} \mathrm{C}\right.$ và $\left.4^{\circ} \mathrm{C}\right)$, mầu không tách huyết thanh $\left(22^{\circ} \mathrm{C}\right)$; trong đó các mẫu được thực hiện ở Canada có nhiệt độ thời tiết khác với Việt $\mathrm{Nam}_{L}$ thời gian ngắn hơn (72 giờ) so với 96 giờ và mấu thực hiện ở cả hai điều kiện là tách và không tách huyết thanh, còn mẫu của chúng tôi ngẫu nhiên có thể tách hoặc không tách huyết thanh.

Trong nghiên cứu của Geralyn M.Lambert Messerlian và cộng sự $(2006)^{(6)}$, beta-hCG và AFP giữ ổn định lên tới 9 ngày ở nhiệt độ bảo quản $4^{\circ} \mathrm{C}$, với uE3 thì sự ổn định chỉ trong vòng 6 ngày ở $4^{\circ} \mathrm{C}$ là dấu ấn duy nhất cho thấy sự thay đổi có ý nghĩa thống kê khi bảo quản sau 6 ngày, nồng độ uE3 sẽ tăng cao hơn khi thời gian bảo quản từ 7 ngày cho đến 9 ngày $(5 \%)$.

Với nghiên cứu này, chúng tôi dựa trên số liệu thống kê, các mẫu thu thập ngẫu nhiên ,vận chuyển mẫu từ các phòng khám về phòng xét nghiệm có nhiệt độ bảo quản và quá trình xử lý mẫu khác nhau: thời gian ly tâm, mẫu có thể tách huyết thanh hay không tách huyết thanh. Cho nên, chúng tôi muốn thực hiện nghiên cứu để xem xét sự thay đổi nồng độ các dấu ấn hóa sinh trong bộ xét nghiệm Triple test trước tình hình bảo quản mẫu của các đơn vị có ảnh hưởng đến giá trị nồng độ các dấu ấn hay không. Sau nghiên cứu cho thẩy có sự ảnh hưởng trên cả 3 dấu ấn hóa sinh trong quí 2 thai kỳ.

\section{KẾT LUẬN}

Double test: mẫu thử được bảo quản ở 2$8^{\circ} \mathrm{C}$ trong 96 giờ không làm thay đổi giá trị nồng độ free beta-hCG, PAPP-A nhưng làm giảm $10 \%$ giá trị nguy cơ hóa sinh. Khi bảo quản mẫu 120 giờ ở 2-8 ${ }^{\circ} \mathrm{C}$ nồng độ free beta-hCG không thay đổi, trung vị nồng độ PAPP-A tăng ở tuần thai thứ 11 cao nhất là $16,1 \%$ và nguy cơ sinh hóa giảm khoảng $15 \%$.

Triple test: Thời gian lưu mẫu 48 giờ dẫn đến nồng AFP giảm và UE3 tăng. Lưu mẫu 72 giờ và 96 giờ làm tăng nồng độ AFP. Nồng độ Beta-hCG tăng dần theo thời gian lưu trữ mẫu $48,72,96$ giờ. Thời gian bảo quản mẫu kéo dài, nồng độ beta-hCG có xu hướng tăng lên, AFP và uE3 có sự dao động.

\section{TÀI LIỆU THAM KHẢO}

1. Lê Thi Mai Dung, Lương Trân Minh Tiến, Văn Hy Triết (2020). Nồng độ Free $\beta-h C G$ và PAPP-A ở các điều kiện bảo quản mấu ảnh hưởng đến kết quả sàng lọc trước sinh hội chứng Down.Y học Thành phố Hồ Chí Minh. 24: 183

2. Văn Hy Triết (2014). Nghiên cứu ảnh hưởng của thời gian và nhiệt độ bảo quản huyết thanh trên xét nghiệm định lượng PAPP-A và Free $\beta$ HCG huyết thanh trong sàng lọc hội chứng Down. Luận văn thạc sĩ Hóa sinh, Trường Đại học Khoa học Tự Nhiên, Thành phố Hồ Chí Minh.

3. Cruz J. C., G. Minekawa and N.N.Rmaiz, K.H (2010). Effect of temperature on free beta-human chorionic gonadotropin and pregnancy-associated 
plasma protein-A concentration. Ultrasound Obstet Gynecol. 36(2): 141-146.

4. J Massé, G Cherian, J Forest (2000). Transportation of maternal serum specimens for screening for chromosomal aneuploidies: effect of seasonal variations, distance, and freezing on the stability of the biological markers.Clin Biochem. 33 (4):273-277.

5. K Spencer, $\mathbf{P}$ Carpenter, $\mathbf{R}$ Anderson and D.A.Krantz (1993). Stability of intact chorionic gonadotropin (hCG) in serum, liquid whole blood, and dried whole-blood filter-paper spots: impact on screening for Down syndrome by measurement of free beta-hCG subunit. Clin Chem. 39(6): 1064-1068.
6. Lambert-Messerlian G. M. E, E. E.Malone and G.E.C.F.D. Palomaki, J.A.D'Álton,M.E (2006). Stability of first- and second-trimester serum markers after storage and shipment. Prenat Diagn. 26 (1):17-21

7. Louise F Brown C. H. S., Graham Tydeman (2011). Stability of inhibin A and unconjugated oestriol in the second trimester of pregnancy.Ann Clin Biochem. 48:72-74.

8. Nicholas J. Cowans A. S., Johanna $H_{\text {., }}$ and a.K.S.Minna-Maarit Makel. (2010). PAPP-A and free $\beta$ hCG stability in first trimester serum using PerkinElmer AutoDELFIA and DELFIA Xpress systems. Prenatal Diagnosis. 30: 127-132.

\title{
ĐÁNH GIÁ SHUNT GAN-PHỔI Ở BÊNHH NHÂN UNG THƯ BIỂU MÔ TẾ BÀO GAN TRƯớC XA TRI TRONG CHỌN LỌC BẰNG HẠT VI CẦU PHÓNG XẠ ${ }^{90} Y$
}

\author{
Nguyễn Duy Anh*, Phạm Văn Thái*, \\ Trần Hải Bình**, Trịnh Hà Châu**, Lể Văn Khảng**
}

\section{TÓM TẮT}

Muc tiêu: Nhân xét môt số yễu tố liên quan tới giá trị shunt gan-phổi khi ghi hình bằng 99mTc-MAA ở các bênh nhân ung thư biểu mô tế bào gan (UTBMTBG) trước xa trị trong chọn lọc bằng hạt vi cầu phóng xa ${ }^{90} Y$. Phương pháp nghiên cứu: Nghiên cứu tiến hành trên 44 bệnh nhân được chẩn đoán UTBMTBG và điều trị tại trung tâm $Y$ hơc hat nhân \& Ung bướu, bệnh viện Bạch Mai từ nằm 2019 đến 2021. Các bênh nhân được ghi hình bằng máy SPECT với 99mTc-macroaggregted albumin (MAA) trước khi điều trị phương pháp xạ trị trong chọn lọc (Selective Internal Radiotherapy - SIRT) bằng hạt vi cầu phóng xa ${ }^{90} Y$. Giá tri shunt gan-phổi được tính toán và đánh giá mức độ liên quan với một số yếu tố lâm sàng, cận lâm sàng. Ngoài ra, theo dối các bênh nhân theo thời gian để kiểm tra có hay không mối tương quan giữa giá trị shunt gan-phổi với đáp ứng điều trị bằng SIRT. Kết quả: Giá trị shunt gan-phổi trung bình 5,3 33,7\%, nhỏ nhất 1,2\%, lớn nhất 19\% (sau đó không điều trị bằng SIRT). Khi ghi hình bằng máy SPECT có 03 bệnh nhân có sự tập trung ${ }^{99 m}$ Tc-MAA ngoài gan (vị trí túi mật và dạ dày). Khảo sát cho thây rằng có thể có mối liên hệ có ý nghĩa thống kê giữa đặc điểm giới của bênh nhân, mức độ xơ gan, kích thước khối u, mức độ tăng sinh mạch của khổi u với giá trị shunt gan-phổi. Ban đầu thấy rằng giá trị shunt gan-phổi không phải là một yếu tố tiên lượng sự đáp ứng với điều trị SIRT của bệnh nhân UTBMTBG, nhưng có thể thây rằng giá trị shunt liên quan có ý nghĩa thống kê tới nguy cơ di

**TT Y hoc hat nhân và Ung bướu, bênh viẹn Bạch Mai Chịu trách nhiệm chính: Nguyễn Duy Anh

Email: duyanh19901@gmail.com

Ngày nhận bài: 14.9.2021

Ngày phản biên khoa hoc: 12.11.2021

Ngày duyệt bài: 19.11.2021 căn phổi của khối u gan ác tính. Kết luân: Ghi hình với ${ }^{99 m T c-M A A ~ t i ́ n h ~ s h u n t ~ g a n-p h o ̂ ̉ i ~ t r u ̛ o ̛ ́ c ~ đ i e ̂ ̀ u ~ t r i ̣ ~ S I R T ~}$ là cân thiết vì nó giúp giảm thiểu nguy cơ tai biến xảy ra do xạ trị, tăng cường tính an toàn và hiệu quả điều tri. Giá trị shunt gan-phổi hứa hen còn mang lai nhiều thông tin hữu ích không chỉ cho riêng SIRT mà kể cả các bệnh nhân điều trị phương án khác.

\section{SUMMARY}

ASSESSMENT OF HEPATOPULMONARY SHUNTING IN HEPATOCELLULAR CARCINOMA PATIENTS BEFORE SELECTIVE INTERNAL RADIATIONTHERAPY WITH Y-90

Objectives: To evaluate some factors related to the value of hepatopulmonary shunting when imaging with 99mTc-MAA in patients with hepatocellular carcinoma (HCC) before selective internal radiation therapy with ${ }^{90}$ Y. Methods: The study was conducted on 44 patients diagnosed with HCC and treated at the Nuclear Medicine \& Oncology Center, Bach Mai Hospital from 2019 to 2021. The patients were recorded by SPECT machine with $99 \mathrm{mTC}$ macroaggregted albumin (MAA) prior to Selective Internal Radiation Therapy (SIRT) with ${ }^{90} \mathrm{Y}$ radioactive microspheres. Hepatopulmonary shunting values were calculated and assessed in relation to a number of clinical and subclinical factors. In addition, follow-up patients over time to check whether there is a correlation between hepatopulmonary shunting values and response to SIRT treatment. Results: The average value of hepatopulmonary shunting was $5.3 \pm 3.7 \%$, the smallest $1.2 \%$, the maximum $19 \%$ (then no SIRT treatment). When recording with the SPECT machine, there were 03 patients with a concentration of 99mTc-MAA outside the liver (position of the gallbladder and stomach). The survey showed that there could be a statistically significant relationship between the patient's gender 